\title{
Antioxidant Effect of Hydrogen Nanobubble Contributes to Suppression of Tumor Cell Growth
}

\author{
Hiromi Kurokawa ${ }^{1}$, Hirofumi Matsui ${ }^{1}$, Hiromu Ito ${ }^{2}$, Atsushi Taninaka ${ }^{3}$, Hidemi Shigekawa ${ }^{3}$, Gjergj \\ Dodbiba $^{4}$, Yuezhou Wei ${ }^{5}$ and Toyohisa Fujita ${ }^{5 *}$ \\ ${ }^{1}$ Faculty of Medicine, University of Tsukuba, Ibaraki, Japan \\ ${ }^{2}$ Graduate School of Medical and Dental Sciences, Kagoshima University, Kagoshima, Japan \\ ${ }^{3}$ Faculty of Pure and Applied Sciences, University of Tsukuba, Japan \\ ${ }^{4}$ Graduate School of Engineering, the University of Tokyo, Japan \\ ${ }^{5}$ College of Resources, Environment and Materials, Guangxi University, China \\ *Corresponding author: Toyohisa Fujita, College of Resources, Environment and Materials, Guangxi University, China
}

\section{ARTICLE INFO}

Received: 慧 July 15, 2019

Published: 幽 July 22, 2019

Citation: Hiromi K, Hirofumi M, Hiromu I, Atsushi T, Hidemi S, Gjergj D, Yuezhou W, Toyohisa F. Antioxidant Effect of Hydrogen Nanobubble Contributes to Suppression of Tumor Cell Growth. Biomed J Sci \& Tech Res 19(5)-2019. BJSTR. MS.ID.003361.

\section{ABSTRACT}

The antitumor effect of hydrogen nanobubble was evaluated in vitro and in vivo. Cancer cell growth was inhibited in the hydrogen nanobubble-containing medium compared to the non-containing medium (in vitro). Tumor growth was significantly suppressed in the middle stage of transplantation (in vivo). We reported that hydrogen nanobubbles is a ROS scavenger, therefore apoptosis due to ROS reduction may be induced in these results.

Keywords: Antioxidant; Hydrogen Nanobubble; Tumor Cell

\section{Introduction}

Hydrogen is known to have a strong antioxidant effect, derived by its high reducing property [1]. However, hydrogen is difficult to dissolve in water. Thus, an exclusive device is required to generate the hydrogen water $[2,3]$. To clear this problem, we investigated the stable supply of hydrogen by nanobubbes. In our previously report, hydrogen nanobubbles eliminated the superoxide as compared to other gases in cell-free systems [4]. In this study, we examined the effect of hydrogen nanobubbles on cancer growth in vitro and in vivo.

\section{Materials and Methods}

\section{Cell Culture}

Rat cancerous gastric mucosa cell-line (RGK1) was established by exposing 1-Methyl-3-nitro-1-nitrosoguanidine to rat gastric mucosal cells. RGK1 was cultured in Dulbecco's modified Eagles/
F12 medium without L-glutamine (Sigma-Aldrich Japan K.K., Tokyo, Japan). Mouse Lewis lung carcinoma (LLC) cells were obtained from Riken Cell Bank (Tukuba, Japan). LLC was cultured in RPMI1640 medium (Wako Pure Chem. Ind., Ltd., Osaka, Japan). The culture medium contained $10 \%$ heat-inactivated fetal bovine serum (Biowest, Kansas City, MO, U.S.A.) and 1\% penicillin/streptomycin (Wako). Cells were cultured in a $37^{\circ} \mathrm{C}$ incubator in an atmosphere of $5 \% \mathrm{CO}_{2}$ in air.

\section{Preparation of $\mathrm{H}_{2}$-Medium and $\mathrm{H}_{2}$-Water}

The $99.99999 \%$ hydrogen gas was bubbled into water for cell culture (Millipore, Billerica, MA, U.S.A.) using a pore type porous ceramic sparger, which has $500 \mathrm{~nm}$ of mean pore diameter for 30 min. Using this water, $\mathrm{H}_{2}$-medium was prepared with Dulbecco's modified Eagles/F12 medium (Sigma-Aldrich) and $14.3 \mathrm{mM}$ $\mathrm{NaHCO}_{3}$ (Wako). $\mathrm{H}_{2}$-water was prepared using Gas \& Water Double Hydrogen Bottle ${ }^{\circledR}$ (WOO co., Ltd., Tokushima, Japan). 


\section{Cell Viability Assay}

Cell viability was examined using Cell Counting Kit-8 (CCK-8) (Dojindo, Tokyo, Japan) according to the manufacturer's protocol. RGK1 was cultured on 96-well plates at $2.5 \times 10^{3}$ cells/well and incubated overnight. The supernatant was aspirated, and the medium replaced to $\mathrm{H}_{2}$-medium. Cytotoxicity was determined by incubating cells at $37^{\circ} \mathrm{C}$ for $24 \mathrm{~h}$. Cells were incubated with $10 \%$ CCK-8 reagent. Absorbance at $450 \mathrm{~nm}$ was measured by a DTX880 multi-mode microplate reader (Beckman Coulter, Brea, CA, USA).

\section{Animal Protocol}

Eight-week-old male C57BL/6 mice were used in vivo assay. Mice were purchased from Japan SLC Inc. (Hamamatsu, Japan).
Animal protocol was approved by the University of TSUKUBA Standing Committee on Animals. Mice were injected in the flank subcutaneously with LLC cells $\left(2 \times 10^{6}\right)$. After tumor implantation, mice were obtained free access to water or $\mathrm{H}_{2}$-water. The tumor size was measured at 13, 16, 19 and 22 days after tumor implantation. The tumor volume was calculated as follows: Volume $(\mathrm{mm} 3)=$ length $\mathrm{x}$ width ${ }^{2} \mathrm{x}$ 0.5. On Day 22, mice were euthanized, and tumors were calculated.

\section{Results and Discussion}

We investigated that the effect of $\mathrm{H}_{2}$-mediun for cancer cells. Compare the culture medium (Control), cell viability of $\mathrm{H}_{2}$-medium was significantly decreased (Figure $1 \mathrm{~A}$ ). Thus, $\mathrm{H}_{2}$-water can inhibit cancer cell growth.
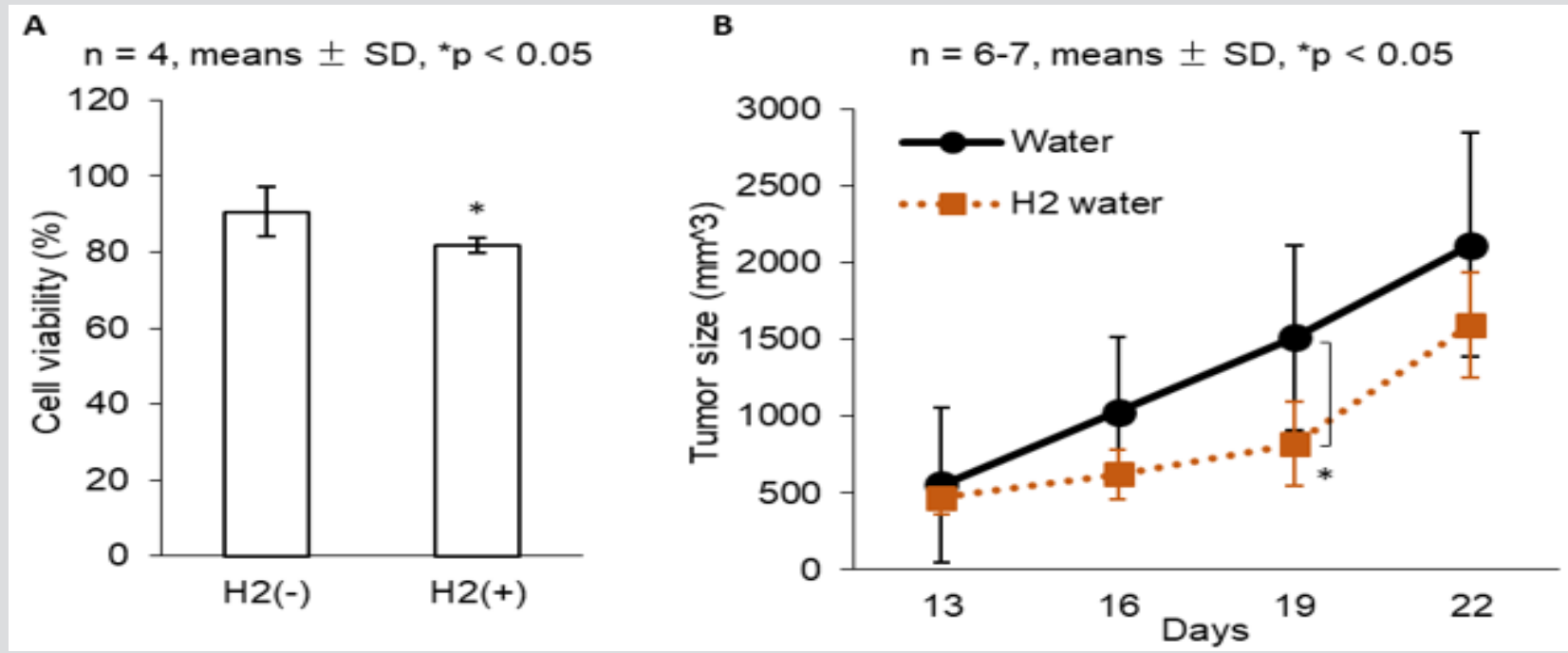

Figure 1: The effect of $\mathrm{H}_{2}$-medium or $\mathrm{H}_{2}$-water

a) Cell viability assay in RGK1.

b) Time dependent of tumor volume in tumor bearing mice.

The time dependent of tumor size in tumor bearing mice is shown in Figure 1B. The tumor size in the $\mathrm{H}_{2}$-water group was smaller than that of the control group, and a significant difference was observed at 19 days after tumor implantation. From this result, $\mathrm{H}_{2}$-water can inhibit tumor growth. In this study, we indicated the anti-tumor effect of $\mathrm{H}_{2}$-medium and water in in vitro and in vivo. It has been reported that tumor growth is suppressed by hydrogen nanobubble [2,3]. Compared to these methods, our method is more convenient for producing nanobubbles using a pore type porous ceramic sparger for hydrogen supply. We considered that we can provide a more accessible method to obtain the antitumor effect by hydrogen nanobubbles. We have investigated the effects of antioxidants such as monascus pigment and curcumin [5,6]. These antioxidants inhibited the tumor growth. As a result of the reduction of acid ceramidase due to the reduction of ROS, it has been clarified that the accumulation of ceramide is increased, thereby inducing apoptosis [7-9]. Hydrogen nanobubbles are also considered to be due to this mechanism because they have high scavenging ability to superoxide.

\section{Conclusion}

The hydrogen nanobubbles induced inhibition of cell growth. The mechanism of this effect suggested the induction of apoptosis by ROS reduction.

\section{Acknowledgement}

This study was supported by Kakehashi projects in FY2018 (TK18-05) and WOO co., Ltd.

\section{References}

1. Ohsawa I, Ishikawa $M$, Takahashi $K$, Watanabe $M$, Nishimaki $K$, et al. (2007) Hydrogen acts as a therapeutic antioxidant by selectively reducing cytotoxic oxygen radicals. Nat Med 13(6): 688-694.

2. Saitoh Y, Okayasu H, Xiao L, Harata Y, Miwa N (2008) Neutral pH hydrogen-enriched electrolyzed water achieves tumor-preferential 
clonal growth inhibition over normal cells and tumor invasion inhibition concurrently with intracellular oxidant repression. Oncol Res 17(6): 247-255.

3. Asada R, Kageyama K, Tanaka H, Matsui H, Kimura M, et al. (2010) Antitumor effects of nano-bubble hydrogen-dissolved water are enhanced by coexistent platinum colloid and the combined hyperthermia with apoptosis-like cell death. Oncol Rep 24(6): 1463-1470.

4. Fujita T, Zhang L, Ponou J, Dodbiba G, Han Z, et al. (2019) Nanobubble mixed solution of carbon dioxide and hydrogen for removing hydroxyl radical and superoxide anion free radicals in water. International journal of current advanced research.

5. Kurokawa H, Ito H, Matsui H (2017) Monascus purpureus induced apoptosis on gastric cancer cell by scavenging mitochondrial reactive oxygen species. J Clin Biochem Nutr 61(3): 189-195.

\section{ISSN: 2574-1241}

DOI: 10.26717/BJSTR.2019.19.003361

Toyohisa Fujita. Biomed J Sci \& Tech Res

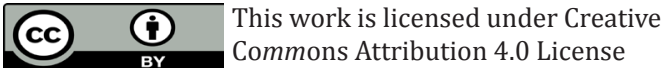

Submission Link: https://biomedres.us/submit-manuscript.php
6. Thangavel S, Yoshitomi T, Sakharkar MK, Nagasaki Y (2015) Redox nanoparticles inhibit curcumin oxidative degradation and enhance its therapeutic effect on prostate cancer. J Control Release 209: 110-119.

7. Doan NB, Nguyen HS, Montoure A, Al Gizawiy MM, Mueller WM, et al. (2017) Acid ceramidase is a novel drug target for pediatric brain tumors. Oncotarget 8(15): 24753-24761.

8. Seelan RS, Qian C, Yokomizo A, Bostwick DG, Smith DI, et al. (2000) Human acid ceramidase is overexpressed but not mutated in prostate cancer. Genes Chromosomes Cancer 29(2): 137-146.

9. Camacho L, Meca Cortes O, Abad JL, Garcia S, Rubio N, et al. (2013) Acid ceramidase as a therapeutic target in metastatic prostate cancer. J Lipid Res 54(5): 1207-1220.

$\begin{array}{ll}\text { BIOMEDICAL } & \text { Assets of Publishing with us } \\ \text { RESEARCHES } & \text { - Global archiving of articles } \\ & \text { - Immediate, unrestricted online access } \\ & \text { - Rigorous Peer Review Process } \\ & \text { - Authors Retain Copyrights }\end{array}$

